\title{
Polychloroprene Rubber/Reduced Graphene Oxide (RGO) Nanomembranes for Pervaporation Separation of Azeotropic Mixtures
}

\author{
Maya M.G ${ }^{a, b}$, Soney C. George ${ }^{a, b,{ }^{*}}$, Thomasukutty Jose ${ }^{a}$ and Sabu Thomas ${ }^{b}$ \\ ${ }^{a}$ Centre for Nanoscience and Technology, Department of Basic Sciences, Amal Jyothi College of \\ Engineering, Kanjirappally, Kottayam. Kerala, India \\ ${ }^{b}$ International and Inter University Centre for Nanoscience and Nanotechnology, Mahatma Gandhi University, \\ Kottayam, Kerala, India
}

\begin{abstract}
Chloroprene rubber is a high performance elastomer with remarkable ageing, heat and oil resistance. A new class of elastomeric nanocomposite was prepared by incorporating reduced graphene oxide (RGO) into chloroprene rubber (CR). RGO is synthesised from natural graphite, through GO route via Hummer's method. This paper focuses on the influence of reduced graphene oxide on chloroprene rubber based elastomeric composites and their pervaporation separation of azeotropic liquid mixtures. The effect of concentration of RGO on separation factor, pervaporation separation index (PSI) and flux of the membranes were analysed. Chloroprene loaded with $0.9 \mathrm{phr}$ (parts per hundred rubber) RGO shows an improved permeation rate among all other membranes while chloroform/acetone (80/20) azeotropic liquid mixture was used as feed solution. Flux increases with increasing the concentration of filler, reaches an optimum value and then decreases. Interestingly PSI also shows similar trend.
\end{abstract}

Keywords: Pervaporation, graphene oxide, chloroprene rubber, azeotropic liquid mixtures, flux.

\section{INTRODUCTION}

Membrane based separation technology is one of the widely used technique for purification, concentration and separation of fluid mixtures. Pervaporation is a promising alternative to conventional energy intensive technologies like azeotropic or extractive distillation in liquid mixtures. Separation through pervaporation is being economical, safe and ecofriendly too. In this regard, pervaporation can be considered as a 'clean technology'; especially it is well suited for the treatment of volatile organic compounds. Separation of azeotropic, close boiling and heat sensitive liquid mixtures by membrane based pervaporation technique has been carried out extensively; because of the potential industrial utility of this approach [1]. The term pervaporation was first named by Kober [2] and patented by Binning and Lee [3]. Compared to conventional techniques such as distillation, pervaporation is more attractive due to its high separation efficiency, energy saving and cost effectiveness [4].

Membrane separation by pervaporation involving the partial vaporization of a liquid mixture through a dense membrane whose downstream side is usually kept under vacuum [5]. Generally, separation by

*Address correspondence to this author at the Centre for Nanoscience and Technology, Amal Jyothi College of Engineering, Kanjirappally, Kottyam, Kerala, India; Tel: +919447870319; E-mail: soneygeo@gmail.com pervaporation can be performed using membranes based on the solution-diffusion mechanism of transport. Mass transport across a permselective membrane involves three consecutive steps [6] they are, permeant dissolves in the feed side of the membrane, diffusion of all the permeant through the membrane and permeant evaporates to the downstream side of the membrane. It indicate that, an ideal polymer for pervaporation membrane should have solubility parameter very close to the component to be selectively permeated so that the membrane sorption of this permeant is high. But there is a contrary; the membrane sorption of the other permeant must be minimum, which requires its solubility parameter to be far apart from that of the membrane polymer [7]. Potential applications of pervaporation is in the areas of; removal of water from organic solvents and their mixtures [8,9], separation of organic solvents from aqueous media $[10,11]$ and separation of liquid organic mixtures [12, 13].

In the field of pervaporation separation of azeotropic mixtures, several research reports for the removal of organics from aqueous solutions $[14,15]$ are available. The selection of polymer blend membrane as a novel material for the pervaporation separation process is worth probing one. The pervaporation performance of polymer blend membranes made from poly (acrylic acid) and poly (vinyl alcohol) was found to be very useful for the selective separation of alcohols from toluene [16]. The pervaporation separation characteristics of natural rubber membranes were 
investigated with chlorohydrocarbon acetone mixtures [17]. The effects of crosslink density and the number of crosslinks on the pervaporation behavior were studied in detail. Silicone rubber membranes were prepared for the pervaporation studies by Uragami and Shinomia [18] and they observed higher selectivity during separation process. The pervaporation properties of PVA/PVP blend membranes crosslinked by gluteraldehyde and a water soluble diazo compound (DAS) in the separation of ethanol-water mixture was reported by $\mathrm{Hu}$ and co-workers [19]. It was found that the pervaporation performance of the membranes was changed along with the PVP content and the membrane selectivity was improved with crosslinking. Recently CNTs are very widely used in the pervaporation separation process. MWCNT/ PVA blend membranes were prepared by Jae-Hyun Choi et al. [20] for the separation of water- ethanol mixture. It was noticed that the crystallinity of the PVA matrix decreased by increasing the amount of MWCNT and the performance of the membranes was influenced by the diameter of MWCNT.

For pervaporation separation process different types of polymer membranes were used. But the use of polychloroprene rubber based nanocomposite membranes in separation process is very few. Interestingly these membranes possess good mechanical and thermal properties. To the best of our knowledge, the use of chloroprene rubber/RGO membranes for pervaporation separation process has not yet been reported. So the main goal and novelty of our work is to prepare chloroprene/RGO composite membranes and to examine the pervaporation performance using chloroform- acetone (80/20) azeotropic liquid mixture. The separation efficiency of the membrane has been evaluated as a function of concentration of RGO.

\section{EXPERIMENTAL PART}

\subsection{Materials}

Polychloroprene rubber (CR) was obtained from DuPont, USA (W-grade) with fast crystallization tendency, ML1+4[@100 $\mathrm{C} 7+/-1$. Natural graphite powder was procured from Sigma Aldrich. Other chemicals $\left(\mathrm{NaOH}, \mathrm{NaNO}_{3}\right.$ and $\left.\mathrm{KMnO}_{4}\right)$ of analytical grade and $98 \% \mathrm{H}_{2} \mathrm{SO}_{4}, 30 \% \mathrm{H}_{2} \mathrm{O}_{2}$ were purchased from Merck Ltd, Mumbai, and they were used as received without any further purification. Zinc oxide, stearic acid and magnesium oxide powders are employed in this study were bought from NICE chemicals. Ethylene thio-urea (ETU) with a commercial name NA22 and antioxidant 6-PPD [N(1,3-dimethylbutyl)-N'-phenyl-P-phenylenediamine] $\left(\mathrm{C}_{18} \mathrm{H}_{24} \mathrm{~N}_{2}\right)$ were obtained from Merck India Ltd.

\subsection{Preparation of $R G O / C R$ Nanomembranes}

RGO was synthesised from natural graphite, through $\mathrm{GO}$ route via Hummer's method [21, 22]. All the composites were compounded according to the formulation given in Table 1. The CR/ RGO composites were compounded according to ASTM D 3182 with the aid of a two roll mixing mill $(150,300 \mathrm{~mm})$. $\mathrm{MgO}$ and $\mathrm{ZnO}$ are the vulcanizing agents but also functions as an acid acceptor. $\mathrm{MgO}$ is added first during the compounding time and $\mathrm{ZnO}$ is added last to avoid the tendency to scorch. The compounded rubber was cured using a hydraulic press under a pressure of 120 bars at $150^{\circ} \mathrm{C}$ to the optimum cure $\left(t_{90}\right)$. Thin membranes prepared with a thickness of approximately 0.4-0.6 $\mathrm{mm}$. In order to study the effect of varying concentration of RGO on the pervaporation performance of chloroprene rubber, 6 set of samples were prepared. In those samples, the RGO concentration ranges from $0,0.3,0.6,0.9,1.5 \& 2.5$

Table 1: Formulation of mixes in parts per hundred rubber

\begin{tabular}{|c|c|c|c|c|c|c|}
\hline Ingredients (phr) & CGO & CG1 & CG2 & CG3 & CG4 & CG5 \\
\hline Chloroprene rubber (CR) & 100 & 100 & 100 & 100 & 100 & 100 \\
\hline Stearic acid & 0.5 & 0.5 & 0.5 & 0.5 & 0.5 & 0.5 \\
\hline $\mathrm{MgO}$ & 4 & 4 & 4 & 4 & 4 & 4 \\
\hline Antioxidant-(6-PPD) & 1.5 & 1.5 & 1.5 & 1.5 & 1.5 & 1.5 \\
\hline RGO & 0 & 0.3 & 0.6 & 0.9 & 1.5 & 2.5 \\
\hline $\mathrm{ZnO}$ & 5 & 5 & 5 & 5 & 5 & 5 \\
\hline Ethylene-thio urea (NA22) & 0.5 & 0.5 & 0.5 & 0.5 & 0.5 & 0.5 \\
\hline
\end{tabular}


phr, and are denoted as samples CG0, CG1, CG2, CG3, CG4 and CG5 respectively.

\subsection{Pervaporation Experiments}

Pervaporation experiments were performed using the system displayed in Figure 1. [23]. Azeotropic composition of chloroform- acetone mixture in the ratio of $80: 20$ was used as the feed solution. All the membranes were first immersed and swollen in the respective feed mixture at room temperature for 'pretreatment' of the membrane and it is essential for the successful pervaporation process. Pre-treated membranes were further placed in the permeation cell. The feed was dispersed through the pervaporation cells from a feed reservoir kept at room temperature. The permeation side of the membrane was completely evacuated by vacuum pump and downstream pressure was lower than $3 \mathrm{~mm}$ of $\mathrm{Hg}$. The permeate was collected in a glass trap under liquid nitrogen filled flask. The composition of the permeate and feed collected in the glass trap were analyzed by using a Refractometer.

Here the performance of the membranes expressed on the basis of separation factor ( $\alpha$ ), permeation rate $(Q)$, and pervaporation separation index (PSI) [24]. The separation factor based on the composition of feed solution and permeates were calculated as follows:

$\alpha=\frac{\mathrm{Y}_{\mathrm{A}} / \mathrm{Y}_{\mathrm{B}}}{\mathrm{X}_{\mathrm{A}} / \mathrm{X}_{\mathrm{B}}}$

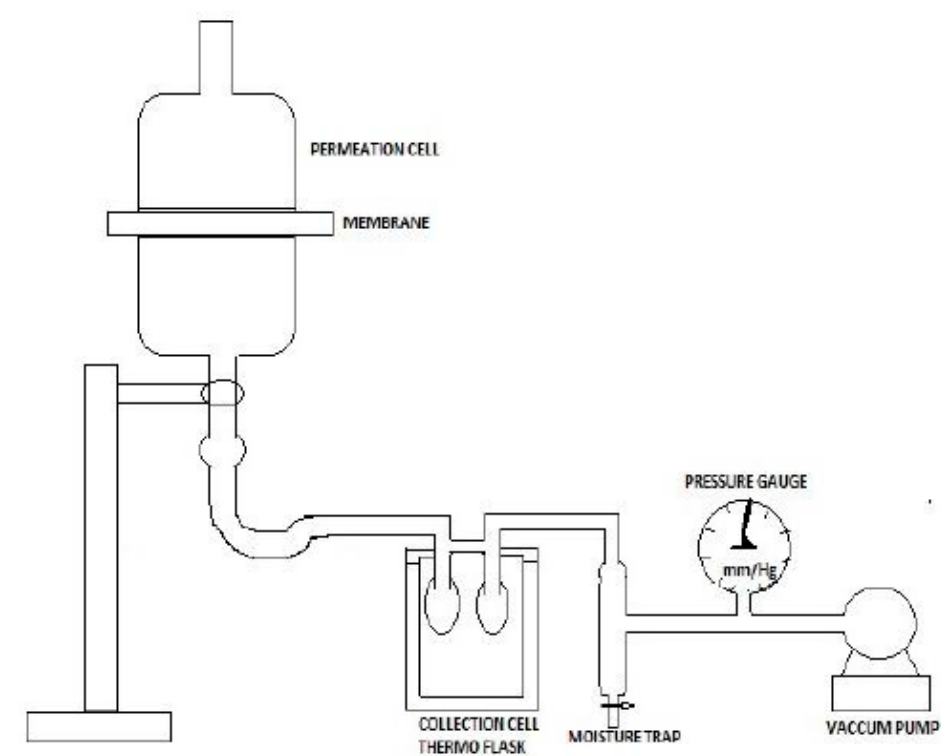

A where, $Y_{\mathrm{A}} \quad Y_{\mathrm{B}}$ represent the weight fraction of chloroform and acetone in the permeate respectively, $X_{\mathrm{A}}$ and $X_{\mathrm{B}}$ are those of the chloroform and acetone in the feed respectively. The permeation rate (Flux), $Q$ was determined by using the equation,

$Q=\frac{\mathrm{M}}{\mathrm{At}}$

where, $\mathrm{M}, \mathrm{A}$ and $\mathrm{t}$ denotes the weight of the permeate $(\mathrm{g})$, effective membrane area $\left(\mathrm{m}^{2}\right)$, and operating time (h), respectively. Pervaporation Separation Index was calculated by the following equation,

$P S I=Q(\alpha-1)$

in which, $Q$ and $\alpha$ are the permeation rate (flux) and separation factor respectively [25].

\subsection{Membrane Characterization}

The state of dispersion of filler in nanocomposites was studied using X-ray diffraction (XRD) studies using a Bruker AXS D8 advance with configuration vertical, and the wave length $1.5406 \mathrm{~A}^{\circ}$.

Transmission electron microscopy (TEM) images provided information about the state of dispersion of nanoparticles in the nanocomposites. TEM analysis were conducted in JEOL-JEM $2100 \mathrm{~F}$ field emission gun transmission electron microscope with an acceleration voltage of $200 \mathrm{kV}$ with low magnification range up to $50 \mathrm{x}$ to $6000 \mathrm{x}$, and resolution point, $0.23 \mathrm{~nm}$.

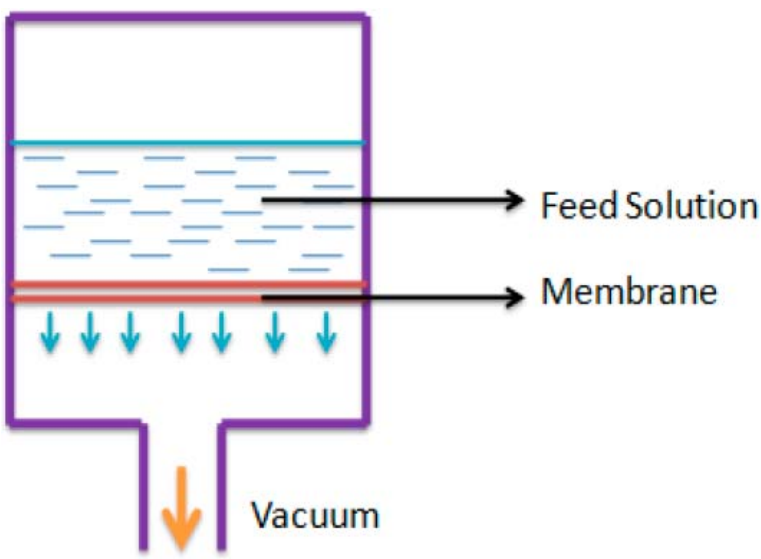

B

Figure 1: Pervaporation apparatus and pervaporation process. 


\section{RESULTS AND DISCUSSION}

\subsection{XRD Analysis}

X-ray diffraction spectrum of $\mathrm{CR} / \mathrm{RGO}$ composite is displayed in Figure 2. It is evident from the figure that, in the XRD of RGO there is strong and sharp diffraction peak at $2 \theta=24.7^{\circ}$ corresponds to an interlayer distance of $3.4 \mathrm{~nm}$; the diffraction peak of pure RGO is disappeared from all $\mathrm{CR} / \mathrm{RGO}$ composites [26]. It is clearly indicating that, $R G O$ is well exfoliated throughout the whole CR matrix. When polymer layers are inserted between the inter layer of RGO, intercalated structures are formed and are well distributed and dispersed. The disappearance of the XRD peak of RGO is due to the formation of exfoliated CR/ RGO nanocomposite structure. Similar X-Ray diffraction patterns have been reported in graphene elastomeric composites by Zhan et al. [27, 28]. On the other hand the spectrum shows four sharp common peaks in every membrane occurred at $2 \theta=9,28,32$ and $38^{\circ}$ corresponds to an interlayer distance of 9,3 , 2.4 and $2.5 \mathrm{~nm}$ respectively. Subsequently these peaks are present even in the neat sample also, which means that, rubber additives like $\mathrm{ZnO}, \mathrm{MgO}$ along with stearic acid and organic accelerator used in the compounding process, or any intermediate product arising from the vulcanization reaction is responsible for these scattering.

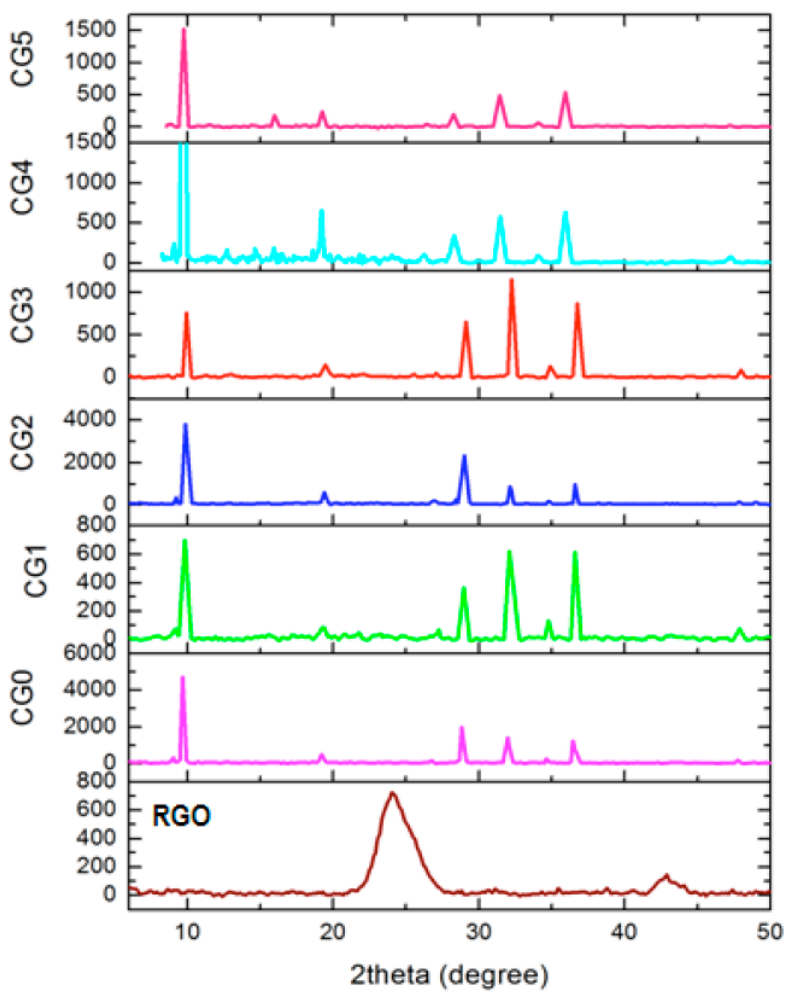

Figure 2: XRD pattern of $\mathrm{CR} / \mathrm{RGO}$ membranes.

\subsection{Transmission Electron Microscopy}

Transmission electron microscopy images provided information about the state of dispersion of nanoparticles in the nanocomposites. Typical TEM micrographs are shown in Figure 3. TEM observations indicate that different RGO layers are well exfoliated and are distributed very nicely throughout the whole CR matrix. In the case of CG2 and CG3 (0.6 and 0.9 phr RGO loaded samples), the state of dispersion of reduced graphene oxide is uniform and the layers are clearly obtained from the TEM images. But at higher filler concentration, the state of dispersion is poor; it depicts the existence of agglomerates in the system, whereas CG2 and CG3 show fine dispersion of RGO with a few agglomerates.

\subsection{Pervaporation Characteristics of CR/RGO Membranes}

In the present study, a novel membrane based on polychloroprene rubber and reduced graphene oxide is used for separating the azeotropic composition of chloroform/ acetone mixture (80/20). The effect of RGO on permeation rate (flux) and separation factor was studied at room temperature, and are given in Figures 4 and 5. Here the pervaporation flux is plotted as a function of filler concentration. The permeate flux is found to be higher in the case of chloroform/acetone azeotropic mixture with $0.9 \mathrm{phr}$ filler (RGO) loaded membranes ie, CG3 membranes, but the flux decreases with the increase of RGO content. From this data, we can understand that the performance of the membrane is very good at very low filler loading. Similar trend was not observed in the case of separation factor ( $\alpha$ ) (Figure 5 ). It may be due to the degree of swelling which increases at higher filler loading resulting in an enhanced flux. But this increased swelling has a negative impact on CR/RGO membrane's selectivity, since the swollen upstream membrane layer might have allowed the liquid molecules to escape through the permeate side [29]. Therefore, permeate composition was reduced and it results a drop in the separation factor.

Pervaporation Separation Index (PSI) is used to evaluate the overall performance of the membranes. Figure 6 shows the change in PSI value as a function of filler loading. From the figure it is revealed that the pervaporation performance increases with increase in concentration of RGO content in the membranes. In the current system, the PSI value indicates that the best 

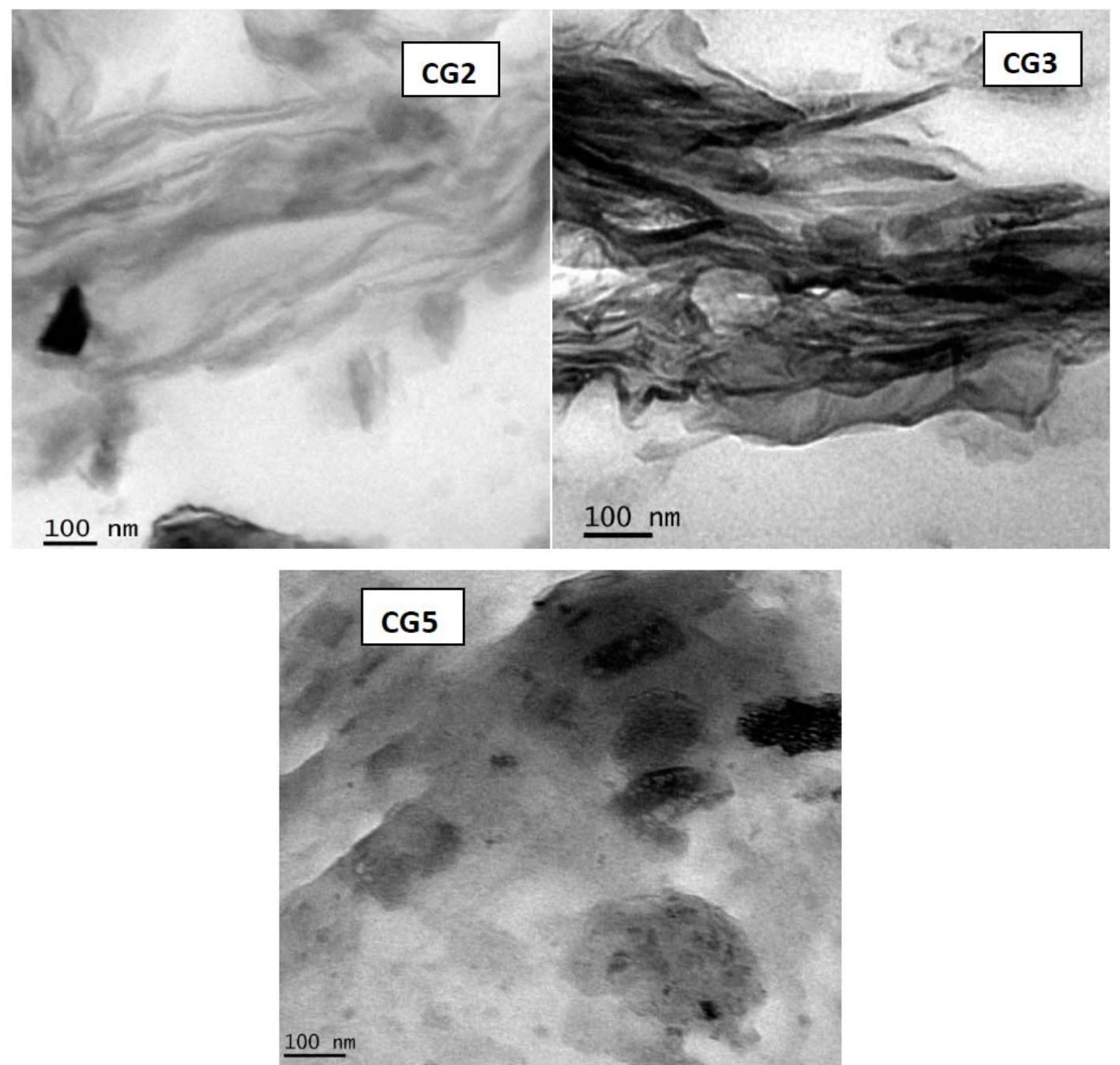

Figure 3: TEM images of the CR/ RGO composite membranes.

overall pervaporation performance is exhibited by the membrane loaded with $0.9 \mathrm{phr}$ RGO.

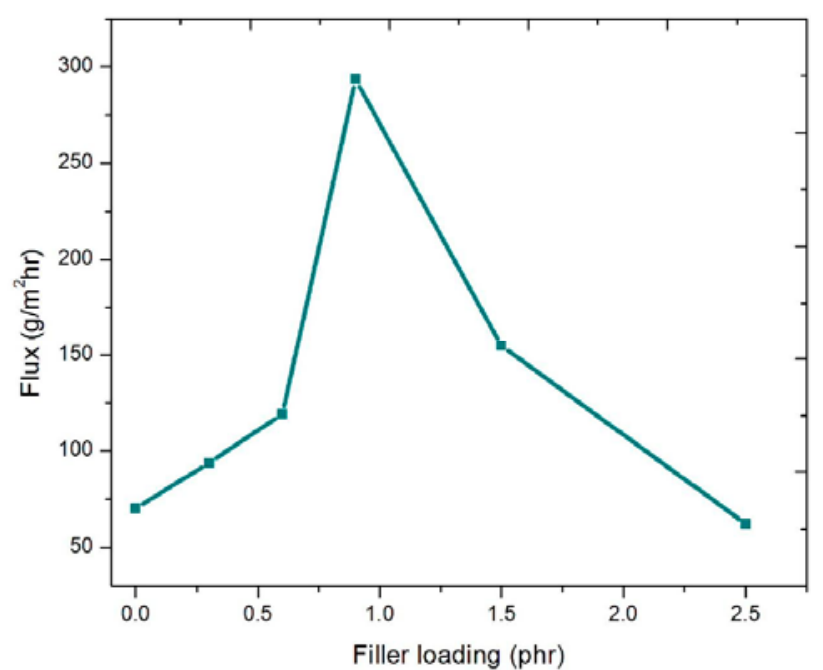

Figure 4: The change of permeation rate with the RGO loading.

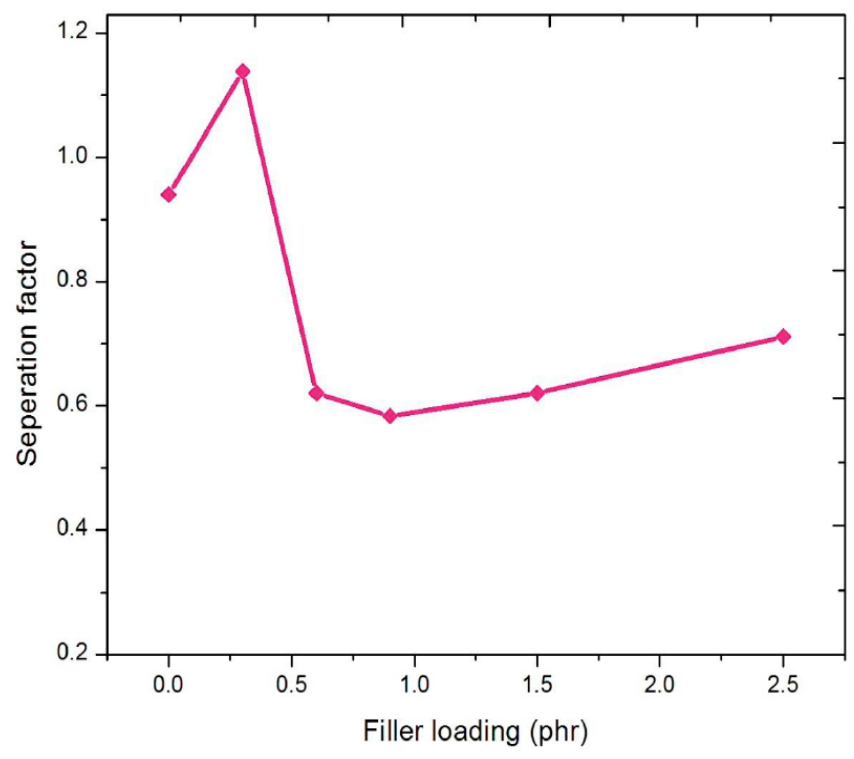

Figure 5: The change of separation factor with the RGO loading. 


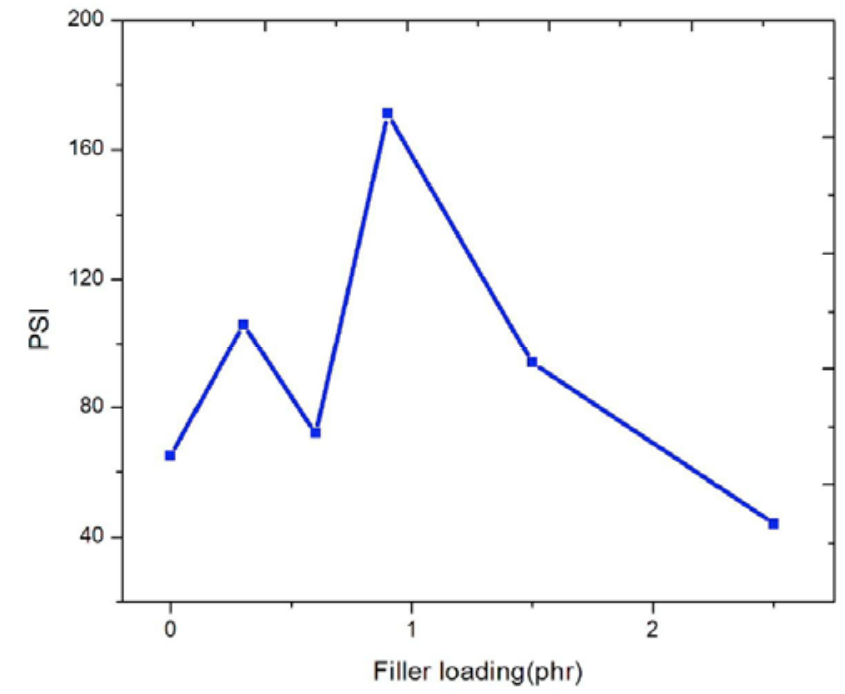

Figure 6: PSI vs Filler content.

\section{CONCLUSION}

The pervaporation performance for the separation of azeotropic mixtures of chloroform/acetone was investigated for polychloroprene rubber/ RGO membranes. The results revealed that the membrane exhibits a higher permeation rate with low amount of RGO. Membranes loaded with 0.9 phr RGO shows good flux. The pervaporation performance increases with increasing the concentration of RGO content in the prepared membranes. The pervaporation separation index (PSI) values also indicate that the best overall pervaporation performance is exhibited by the membrane loaded with $0.9 \mathrm{phr}$ RGO. This is because of the good interaction between RGO and $C R$ which improves the dispersion of $R G O$ in the chloroprene matrix. TEM and XRD analysis also support that the exfoliated RGO was well dispersed in the $C R$ matrix. Thus we can conclude that, the pervaporation of CR/RGO membranes can be applied for the treatment of industrial wastes containing acetone and chloroform at lower concentrations.

\section{ACKNOWLEDGEMENT}

The authors are especially grateful to DST (Order No: SR/S3/ME/0031/2011), New Delhi, India for providing the financial assistance. School of Chemical Science and School of Applied Physics, Mahatma Gandhi University, Kottayam, Kerala India, Department of Physics and Sophisticated Testing and Instrumentation Centre (STIC) -Cochin University of Science and Technology, Kerala, India are also acknowledged here for various analyses.

\section{REFERENCES}

[1] Fleming HL, Slater CS, Pervaporation WSW, Ho KK. Sirkar (Eds.), Membrane Handbook, Van Nostrand Reinhold, New York; 1992; Chapter 10: 105.

[2] Kober PA. Pervaporation, Perstillation. J Am Chem Soc 1917; 39: 944-948. http://dx.doi.org/10.1021/ja02250a011

[3] Binning RC, Lee RJ. Separation, U.S. Patent 2, 1960; 953 : 502.

[4] Huang RYM. Pervaporation Membrane, Membr. Sci and Tech. Series1, Elsevier 1991

[5] Neel J, Huang RYM, Ed. Pervaporation Membrane Separation Process, 1991; Chapter 1.

[6] Noble R.D, Stern S.A, Membr Sepa Tech., Principles and Applications, 1995

[7] Ray SK, Sawant SB, Joshi JB, Pangarkar VG. Development of New. Ind Eng Chem Res 1997; 36: 5265-5276. http://dx.doi.org/10.1021/ie970351v

[8] Brookes; Livingston P.R; A.G. J Membr Sci 1995; 104: 119.

[9] Yang D, Majumdar S, Kovenklioglu S. J Membr Sci 1995; 103: 195.

http://dx.doi.org/10.1016/0376-7388(95)00003-U

[10] Yeon C, Lee KH. J Membr Sci 1996; 109: 257. http://dx.doi.org/10.1016/0376-7388(95)00196-4

[11] Ray S, Ray SK. Effect of Copolymer type. J Membr Sci 2006; 270: 73-87. http://dx.doi.org/10.1016/j.memsci.2005.06.055

[12] Liu F, Liu L, Feng X. Separation of Acetone. Sep Purif Technol 2005; 42: 273-282. http://dx.doi.org/10.1016/j.seppur.2004.08.005

[13] Khayet M, Matsuura T. Pervaporation and Vacuum. AIChE J 2004; 50: 1697-1712.

http://dx.doi.org/10.1002/aic.10161

[14] Dutter BK, Sikdar SK. Separation of Azeotropic. AIChE J 1991; 37: 501.

[15] Lee GT, Kroviddi KR, Greenbag DB. Pervaporation of Trace. J Membr Sci 1989; 47: 183. http://dx.doi.org/10.1016/S0376-7388(00)80867-4

[16] Park HC, Meertens RM, Mulder MHV, Smolders CA. Pervaporation of Alcohol. J Membr Sci 1994; 90: 265. http://dx.doi.org/10.1016/0376-7388(94)80076-6

[17] Unnikrishnan G, Gedam PH, Kishan Prasad VS, Thomas S Separation of n-hexane/acetone. J Appl Polym Sci 1997; 64: 2597.

http://dx.doi.org/10.1002/(SICI)1097 4628(19970627)64:13<2597::AID-APP13>3.0.CO;2-X

[18] Uragami T, Shinomiya H. Macromol Che 1991; 192: 2293. http://dx.doi.org/10.1002/macp.1991.021921009

[19] Hu XH, Ping ZH, Zhu Q, Ding ZM, Ding YD. Pervaportion Properties. Chem J Chin Univ 1998; 19: 647.

[20] Choi J-H, Jegal J, Kim W-N, Choi H-S. J Appl Polym Sci 2009; 111: 2186-2193.

http://dx.doi.org/10.1002/app.29222

[21] Dreyer DR, Park S, Bielawski CW, Ruoff RS. Chem Soc Rev 2010; 39: 228-40 http://dx.doi.org/10.1039/b917103g

[22] Pei S, Cheng H-M. Carbon 2012; 50: 3210-3228. http://dx.doi.org/10.1016/i.carbon.2011.11.010

[23] Dutta BK, Sikdar SK. Separation of Azeotropic. AIChE J 1991; 37: 581.

[24] George SC, Ninan KN, Sabu Thomas. Pervaporation Separation. J Membrane Sci 2000; 176: 131-142. http://dx.doi.org/10.1016/S0376-7388(00)00439-7 
[25] Asman G, Oya S. Separation Characteristics. J Appl Polym Sci 2006; 100: 2030-2039.

http://dx.doi.org/10.1002/app.22613

[26] Huang RYM, Feng X. Dehydration of Isopropanol. Sep Sci Technol 1993; 28: 2035.

http://dx.doi.org/10.1080/01496399308016732

[27] Zhan Y, Wu J, Xia H, Yan N, Fei G. Dispersion and exfoliation; Macromol Mater Eng 2011; 296: 590-602. http://dx.doi.org/10.1002/mame.201000358
[28] Lian H, Li S, Liu K, Xu L. Study on modified graphene. Polym Eng Sci 2011; 51: 2254-60. http://dx.doi.org/10.1002/pen.21997

[29] Anjali Devi D, Smitha B, Sridhar S, Aminabhavi TM. Dehydration of 1,4-dioxane. J Membr Sci 2006; 280: 138147.

http://dx.doi.org/10.1016/j.memsci.2006.01.006 